\title{
Development of Nurse-led Navigation Program for Gastric Cancer Patients with Gastrectomy: Exploring the Effectiveness
}

\author{
HyoNam Lim ${ }^{1}$, JuHee Lee ${ }^{2}$, Taewha Lee ${ }^{2}$, Mo Na Choi ${ }^{2}$, Sanghee Kim³ ${ }^{3}$ Joo-Ho Lee ${ }^{4}$, Sang Eok Lee ${ }^{5}$ \\ ${ }^{1}$ Associate Professor, College of Nursing, Konyang University, ${ }^{2}$ Professor, Mo-Im Kim Nursing Research \\ Institute, College of Nursing, Yonsei University, ${ }^{3}$ Associate Professor, Mo-Im Kim Nursing Research Institute, \\ College of Nursing, Yonsei University, ${ }^{4}$ Professor, Department of Surgery, Uijeongbu Eulji Medical Center, Eulji \\ University, ${ }^{5}$ Associate Professor, Department of Surgery, Konyang University School of Medicine
}

\begin{abstract}
Background: This study aimed to evaluate the effects of a nurse-led navigation program for gastric cancer patients with gastrectomy.

Method: The experimental group consisted of 23 patients and the control group consisted of 22 patientswith gastric cancer after gastrectomy in $\mathrm{K}$ university hospital in Korea.A quasi-experimental study with a nonequivalent control group was used. This study consists of two phases: a methodological study to develop a navigation program for gastric cancer patients and a quasi-experimental study to verify the effects of the navigation program. The navigation program was administered to the experimental group over 3 months with a total of 8 sessions.

Result:The experimental group had lower distress than the control group $(\mathrm{F}=5.298, \mathrm{p}=0.004)$. Theexperimental group had less weight changes than the control group $(F=4.390, p=0.019)$, and the healthcare service satisfaction with regard to nurses was high $(\mathrm{Z}=2.932, \mathrm{p}=0.003)$. However, the quality of life was not significantly different $(\mathrm{F}=5.905, p=0.707)$.

Conclusion: The nurse-led navigation program for gastric cancer patients was effective at reducing distress, improving nutritional status, and increasing satisfaction with healthcare services. It is suggested to conduct long-term follow-up research to measure quality of life changes from the navigation program.
\end{abstract}

Keywords: gastric cancer; navigation program; distress; nutritional status; healthcare service; satisfaction

\section{Introduction}

According to the annual report of cancer statistics, the most common cancer in Korea was gastric cancer ${ }^{[1]}$. This is expected to increase the number of gastric cancer patients, as the incidence rate is the highest compared to other countries such as the United States and Europe. The survival rate after treatment is increased due to early screening, diagnosis and treatment technology development ${ }^{[2]}$. The improvement of cancer patients'

\footnotetext{
Corresponding Author:

JuHee Lee

(JHL@yuhs.ac), 50-1 Yonsei-ro, Seodaemun-gu, Seoul 03722, Korea
}

survival rate led them to recognize cancer as a concept of chronic disease requiring long-term management ${ }^{[3,4]}$.

Recently, due to the change of medical environment, the overall number of days of hospitalization for cancer patients has been shortened and the responsibility for health care has been added to clients and their families ${ }^{[5,6]}$. Patients with gastrectomy experience physiological changes such as malnutrition, dumping syndrome, intestinal obstruction, and psychological changes such as fear, anxiety, depression, and distress due to uncertain prognosis of disease ${ }^{[7-9]}$.

In Korea, nursing intervention for gastric cancer patients was applied to fragmentary interventioni.e., diet 
education and exercise education ${ }^{[10,11]}$. Since systematic, integrated and continuous approach is very important for gastric cancer patients and their families, it is necessary to integrate nutrition education and emotional support for gastric cancer patients.

For the first times, in the 1990s, Dr. Harold Freeman conducted patient navigation program at the Harlem Hospital in United States, lowering barriers to cancer diagnosis and management for the poor ${ }^{[12]}$. According to a 2001 report from the National Cancer Institute, the barriers to cancer treatment were not confined to the poor so that they could be applied to many Americans over all socio-economic levels ${ }^{[13]}$. In 2005, President George W. Bush approved federally funded legislation for patient navigation projects under the Patient Navigator Activity and Chronic Disease Act(H. R. 1812, 2005).In 2012, a new standard was contributed by the American College Board of Cancer Professionals that should be put into practice for cancer programs requiring certification by $2015^{[14]}$.

Patient navigation is an intervention to overcome the obstacles that appear in the process of health care needs and treatment ${ }^{[15]}$. The navigation program is designed to enhance the accessibility of treatment by supporting cancer patients. It focuses on meeting the needs of patients, not uniform and unilateral education by healthcare professionals. Navigators provide timely and qualitative nursing to affect treatment outcomes ${ }^{[16,17]}$.

The navigation program has been applied to patients with various cancer types such as breast cancer, thyroid cancer, and prostate cancer ${ }^{[18-20]}$.Nurse-led navigation programs reported to affect the emotional aspects of the subjects such as uncertainty, pain, fatigue and depression, ultimately enhancing the quality of life ${ }^{[21-23]}$. Nursing services by professional nurses had positive effects on patient satisfaction, compliance with treatment plans, reduction of length of hospital stay andre-hospitalization $^{[24]}$.

The gastric cancer patients were experienced physical and psychological problems and these symptoms have a significant impact on the quality of life ${ }^{[25]}$. Hong and colleagues $^{[26]}$ developed navigation program for newly diagnosed gastric cancer. This program composed of 3 sessions, each of 30 minutes. This navigator focused on nursing interventions that would be provided to patients at pre-treatment period. There was no navigation program for gastric cancer patients who complained of various physical and psychological symptoms after gastric cancer surgery.Therefore, it is necessary to provide integrated nursing interventions for patients diagnosed with gastric cancer appropriate at each time point throughout the treatment process, which will affect physical and psychological adaptation and recovery.

The purpose of this study was to develop and apply a nurse-led navigation program to patients diagnosed with gastric cancer and were admitted to surgery. The hypothesis of this study is that the experimental group that applied the navigation program will have lower distress, better nutrition status, higher quality of life, and higher satisfaction with medical services than the control group.

\section{Methods}

\section{Sample and Setting}

This study consists of two phases: a methodological study to develop a navigation program for gastric cancer patients and a quasi-experimental study with a nonequivalent control group to verify the effects of the navigation program. Convenience samples were confirmed and recruited at $\mathrm{K}$ University Hospitals in Korea.

The study was approved (accreditation no.:KYUH 2015-09-004-002) by the Institutional Review Board (IRB) of the $\mathrm{K}$ university hospital. Patients signed a written consent form before participating in the study. Each twenty-five patients were assigned to the experimental group and control group. The inclusion criteria as follows; (a)patients who had a performance level of 0 or 1 in the Eastern Cooperative Oncology Group performance status (ECOG); (b)patients with an American Society of Anesthesiology (ASA) score of class I to III; (c)no cognitive impairment and able to communicate; (d)patients who are known to have been diagnosed with gastric cancer. The control group data were collected from Oct 2015 to April 2016, and the experimental group were from February to August 2016. 
Patients with distant metastasis, significant complications after gastric cancer surgery, active concurrent multiple cancer were excluded.In the experimental group, 2 subjects were withdrawn due to reoperation and complications, while 3 subjects were dropped from complications in the control group. Finally, a total of 45 subjects participated in this study (Experimental group=22, Control group=23) (Fig. 1).
After the pre-test, the experimental group received a navigation program for 3 months. The intervention was performed by a researcher with 8 years of experience as a nurse practitioner specializing in gastric cancer. The intervention program effectiveness evaluation was examined at the ward and outpatient counseling room at 7 days after surgery, 1 month after surgery, and 3 months after surgery.

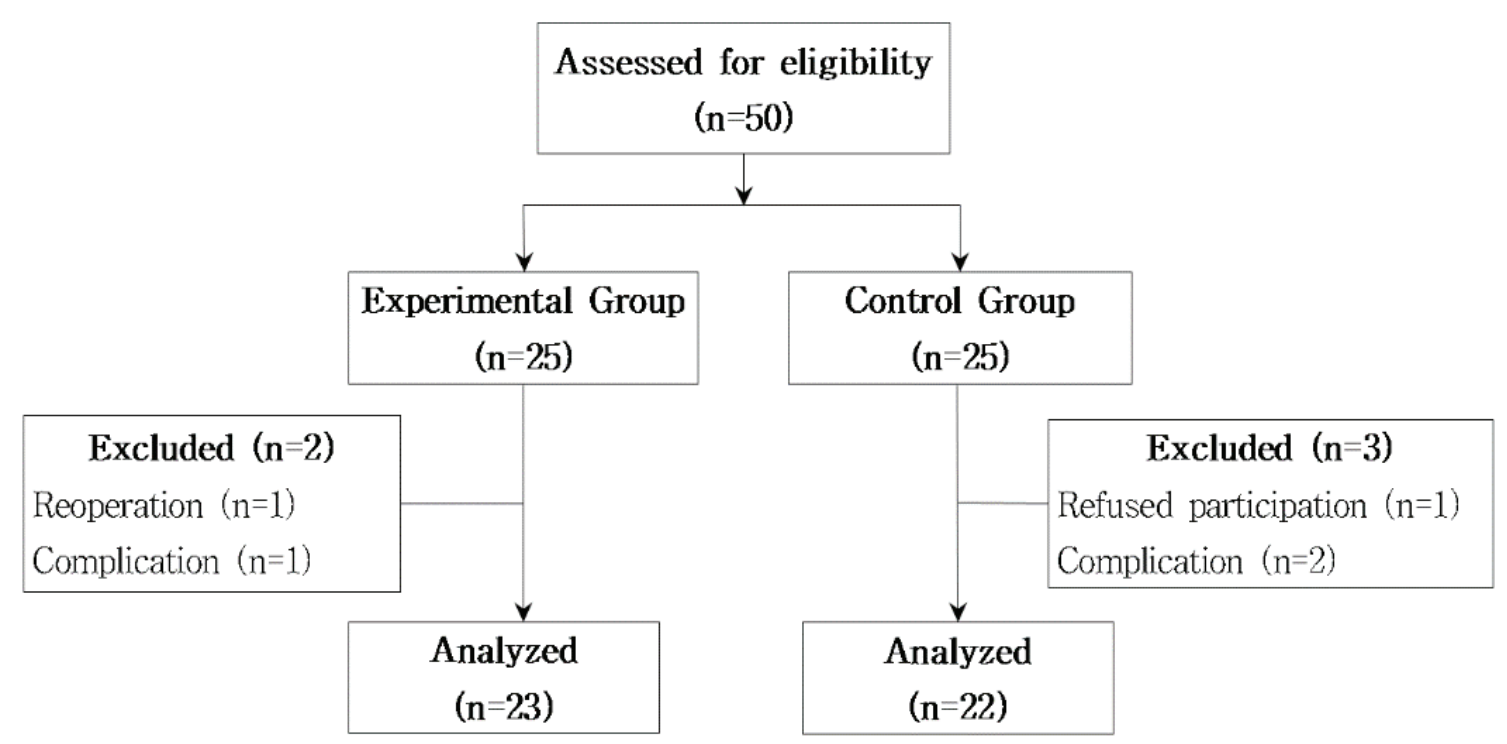

Figure 1. Study participants

\section{Conceptual framework}

The conceptual framework of this study was based ontransition theory proposed by of Meleis and colleagues $^{[27]}$. Transition theory consists of the essence of transition i.e., types, patterns and properties, transition condition, response patterns and nursing therapeutics. The transition care refers to nursing activities that help clients or their families who faced with new environment and situation. Through transition, they accept new changes and adjust the condition ${ }^{[27]}$.

This study was designed to enhance the continuity of nursing care and to promote the empowerment of patients with gastric cancer. The 'Professional Navigation Framework' proposed by Fillion et al ${ }^{[28]}$ guidedan interventional component.This framework was used to enhance continuity of cancer care and the empowerment of patients. Fillion et al ${ }^{[28]}$ suggested the three concept of continuity care; informational, management and relational. In addition, active coping, cancer related self-management and support care were proposed for the patients and caregiver empowerment. Thus, this navigator program provided the information about the gastric cancer and coping strategies.

\section{Navigation program for gastric cancers with gastrectomy}

The first step of designing navigation program was reviewing relevant literatureson gastric cancer interventional studies and nurse-led navigation program for cancer patients. As a result, 16 articles were selected for program development.

Second, focus group interview(FGI) was conducted for gastric cancer patients and healthcare professionals to understand surgical experience and to organize intervention strategies. The 7 gastric cancer surgery clients and 6 healthcare professionals participated. From 
an analysis of FGI interviews with clients who underwent surgery for gastric cancer, 7 themes were derived: postsurgery adjustment period during admission, gastric cancer surgery, discharge, and post discharge; dumping syndrome; satisfying curiosity; diet management; psychological disorder; needs for timely education; and support from healthcare professionals.

An analysis of the FGI with healthcare professionals revealed the following 7 themes: difficulties of gastrectomy patient experiences; nutritional status improvement; patient curiosity after surgery, postoperative care; continuity of care; educational methodsand contents. Based on the reviews and interview results, the intervention contents were composed of 38 items.

Third, a preliminary draft of the navigation program was verified by 6 experts. The content validity index was over 0.80 in each of the 38 items. All items were satisfied the content validity index.

The intervention program was conducted 8 times for 3 months. The 6 times were face-to-face interventions and 2 were telephone consultations (Table 1). Patients were provided with tablet PC containing educational contents and booklets.

Table 1. Composition of the navigation program

\begin{tabular}{|c|c|c|c|c|c|}
\hline Dimension & Themes & & Contents & $\begin{array}{c}\text { Length } \\
(\min )\end{array}$ & Outcome \\
\hline \multirow{8}{*}{$\begin{array}{l}\text { Facilitating } \\
\text { continuity of } \\
\text { care }\end{array}$} & \multirow{4}{*}{$\begin{array}{l}\text { Informational } \\
\text { continuity }\end{array}$} & \multicolumn{2}{|c|}{$\begin{array}{l}\text { Providing educational information package } \\
\text { (booklets and tablet PC) }\end{array}$} & 3 & \multirow{8}{*}{$\begin{array}{c}\text { Satisfaction of } \\
\text { Medical Services }\end{array}$} \\
\hline & & \multirow{3}{*}{$\begin{array}{c}\text { patient } \\
\text { education }\end{array}$} & Pre-surgery patient education & 10 & \\
\hline & & & post-surgery patient education & 10 & \\
\hline & & & Discharge education & 10 & \\
\hline & \multirow[b]{2}{*}{$\begin{array}{l}\text { Management } \\
\text { continuity }\end{array}$} & \multicolumn{2}{|r|}{ Review of test results } & 2 & \\
\hline & & \multicolumn{2}{|c|}{$\begin{array}{l}\text { Coordination with the involved departments } \\
\text { and confirmation of the outpatient schedule }\end{array}$} & 5 & \\
\hline & \multirow[t]{2}{*}{$\begin{array}{l}\text { Relational } \\
\text { continuity }\end{array}$} & \multicolumn{2}{|c|}{$\begin{array}{l}\text { Program orientation with the nurse in } \\
\text { charge } \\
\text { (provide contact information) }\end{array}$} & 3 & \\
\hline & & Answe & ing the phone (if necessary) & 3 & \\
\hline \multirow{12}{*}{$\begin{array}{l}\text { Promoting } \\
\text { patient } \\
\text { empowerment }\end{array}$} & \multirow{3}{*}{$\begin{array}{c}\text { Cancer } \\
\text { self-management }\end{array}$} & Educating & $\begin{array}{l}\text { n gastrointestinal symptoms and } \\
\text { how to manage them }\end{array}$ & 10 & \multirow{3}{*}{ Nutrition Status } \\
\hline & & & Diet education & 15 & \\
\hline & & \multicolumn{2}{|c|}{$\begin{array}{l}\text { Education on chemotherapy side effects and } \\
\text { how to manage them (if necessary) }\end{array}$} & 15 & \\
\hline & \multirow{7}{*}{ Active coping } & \multicolumn{2}{|c|}{ Providing a self-management journal } & 1 & \multirow{7}{*}{ Quality of Life } \\
\hline & & \multicolumn{2}{|c|}{ Need evaluation and symptom management } & 3 & \\
\hline & & & Discussion of cancer & 15 & \\
\hline & & & Coping with stress & 20 & \\
\hline & & \multicolumn{2}{|c|}{$\begin{array}{l}\text { Coping with changes in family and other } \\
\text { interpersonal relationships }\end{array}$} & 10 & \\
\hline & & \multicolumn{2}{|c|}{ Coping with potential fear } & 15 & \\
\hline & & \multicolumn{2}{|r|}{ Maintaining changes } & 15 & \\
\hline & \multirow[b]{2}{*}{ Supportive care } & & oducing a support group & 2 & \multirow[b]{2}{*}{ Distress } \\
\hline & & \multicolumn{2}{|c|}{$\begin{array}{l}\text { Listening, concern, contact, and } \\
\text { encouragement }\end{array}$} & 2 & \\
\hline
\end{tabular}




\section{Instruments}

The distress screening instrument developed by the NCCN(2007)was translated into Korean ${ }^{[29]}$ was used. The instrument comprises of a distress thermometer and distress problem items. Cronbach's $\alpha$ was .80 in the present study. The nutritional status was measured by the Patient-Generated Subjective Global Assessment (PGSGA) ${ }^{[30]}$. In this study, Cronbach's $\alpha$ was .78. Nutrition status, hemoglobin, albumin, and total protein used to verify the biochemical testing. Additionally, weight was measured as an anthropometric index. To evaluate the quality of life of patients with gastric cancer, the general quality of life of patients with cancer (QLQ-30) and the gastric cancer module, the site-specific quality of life for patients with gastric cancer (QLQ-STO22), which were originally developed by European Organization for Research and Treatment of Cancer (EORTC) were used $^{[31]}$. Cronbach's $\alpha$ was .85 in this study. The cancer inpatient satisfaction (IN-PATSAT32) developed by EORTC was used ${ }^{[32]}$ as well. In this study, Cronbach's $\alpha$ values ranged from .79 to .93 .

\section{Data Analysis}

The general characteristics of the experimental and control groups were examined by computing frequencies, percentages, means, and standard deviations. Homogeneity between the groups was tested with descriptive statistics, chi-square test, Fisher's exact test, and Mann-Whitney U test.To examine differences in distress, nutritional status, and quality of life across time, Mauchly's sphericity test was performed, and, then, repeated measures ANOVA was used.The Bonferroni test was used for post-hoc testing. In case ofMauchly's sphericity test showed the homoscedasticity assumption violation, the findings were interpreted using the results of Wilk's lambda of multivariate ANOVA. Difference in satisfaction with healthcare services after the navigation program was completed using a Mann-Whitney U test. The data were analyzed according to per protocol analysis(PPA) principle except for five dropouts.

\section{Results}

\section{General characteristics}

The general characteristics of participantsare represented as Table 2 . The homogeneity test showed no significant differences ingeneral characteristics and dependent variables between two groups.

Table 2. Test of between-group homogeneity (general characteristics) $(n=45)$

\begin{tabular}{|c|c|c|c|c|c|}
\hline \multirow{2}{*}{\multicolumn{2}{|c|}{ Variable }} & $\begin{array}{l}\text { Experimental } \\
\qquad(n=23)\end{array}$ & $\begin{array}{l}\text { Control } \\
(n=22)\end{array}$ & \multirow[t]{2}{*}{$\chi^{2}$ or $Z$} & \multirow[t]{2}{*}{$\mathbf{p}$} \\
\hline & & n(\%) & n(\%) & & \\
\hline \multirow{4}{*}{ Age(yr) } & $\leq 64$ & $13(56.6)$ & $7(31.8)$ & \multirow{3}{*}{2.883} & \multirow{3}{*}{0.279} \\
\hline & $65-74$ & $6(26.1)$ & $8(36.4)$ & & \\
\hline & $\geq 75$ & $4(17.4)$ & $7(31.8)$ & & \\
\hline & & $63.00 \pm 10.78$ & $66.95 \pm 9.82$ & 1.284 & 0.206 \\
\hline \multirow{2}{*}{ Gender } & Male & $16(69.6)$ & $16(72.7)$ & \multirow{2}{*}{0.055} & \multirow{2}{*}{1.000} \\
\hline & Female & $7(30.4)$ & $6(27.3)$ & & \\
\hline \multirow{3}{*}{ Marital status } & Unmarried & $2(8.7)$ & $1(4.5)$ & \multirow{3}{*}{$1.350^{\mathrm{a}}$} & \multirow{3}{*}{1.000} \\
\hline & Married & $20(87.0)$ & $21(95.5)$ & & \\
\hline & Bereaved & $1(4.3)$ & $0(0.0)$ & & \\
\hline
\end{tabular}


Cont... Table 2. Test of between-group homogeneity (general characteristics) $(n=45)$

\begin{tabular}{|c|c|c|c|c|c|}
\hline \multirow{2}{*}{ Religion } & Yes & $11(47.8)$ & $14(63.8)$ & \multirow{2}{*}{1.138} & \multirow{2}{*}{0.37} \\
\hline & No & $12(52.2)$ & $8(36.4)$ & & \\
\hline \multirow{3}{*}{ Education } & Uneducated & $5(31.7)$ & $1(4.5)$ & \multirow{3}{*}{$2.767^{\mathrm{a}}$} & \multirow{3}{*}{$0.29^{7}$} \\
\hline & $\begin{array}{c}\text { Elementary - middle } \\
\text { school }\end{array}$ & $10(43.5)$ & $11(50.0)$ & & \\
\hline & $\geq$ High school & $8(34.8)$ & $10(45.5)$ & & \\
\hline \multirow{2}{*}{ Employment } & Yes & $8(34.8)$ & $5(22.7)$ & \multirow{2}{*}{0.795} & \multirow{2}{*}{0.51} \\
\hline & No & $15(65.2)$ & $17(77.3)$ & & \\
\hline \multirow{3}{*}{ Economic status } & High & $5(21.7)$ & $5(22.6)$ & \multirow{3}{*}{$0.491^{\mathrm{a}}$} & \multirow{3}{*}{0.92} \\
\hline & Middle & $12(52.2)$ & 13(59.1) & & \\
\hline & Low & $6(26.1)$ & $4(18.1)$ & & \\
\hline \multirow{2}{*}{ Stage } & Early & $16(69.3)$ & $11(50.0)$ & \multirow{2}{*}{1.793} & \multirow{2}{*}{0.23} \\
\hline & Advanced & $7(30.4)$ & $15(6)$ & & \\
\hline \multirow{3}{*}{ Surgery method } & $\begin{array}{l}\text { Laparoscopic assisted } \\
\text { distal gastrectomy }\end{array}$ & $15(65.2)$ & $13(59.1)$ & \multirow{3}{*}{$0.370^{\mathrm{a}}$} & \multirow{3}{*}{0.914} \\
\hline & Subtotal gastrectomy & $5(21.7)$ & $5(22.7)$ & & \\
\hline & Total gastrectomy & $3(13.0)$ & $4(18.2)$ & & \\
\hline $\begin{array}{l}\text { Length of hospital } \\
\text { stay(days) }\end{array}$ & $8.08 \pm 1.83$ & $9.04 \pm 2.49$ & -1.236 & 0.221 & 0.297 \\
\hline
\end{tabular}

${ }^{a}$ Fisher's exact test

\section{Distress}

The degree of stress was correlated between two groups according to the measurement time $(\mathrm{F}=5.298$, $\mathrm{p}=0.004)$. In the follow-up analysis, there was a statistically significant difference at 1 month after surgery $(Z=-3.050, p=0.002)$ and 3 months after surgery $(\mathrm{Z}=-3.196, \mathrm{p}=0.001)($ Table 3$)$.

\section{Nutrition Status}

The change of weight was significantly correlated with the experimental group and the control group according to the measurement time $(\mathrm{F}=4.390, \mathrm{p}=0.019)$.
The follow-up analysis showed a statistically significant difference in the postoperative 1 month $(Z=-2.158$, $\mathrm{p}=0.031)$ and the postoperative 3 months $(Z=-2.193$, $\mathrm{p}=0.028$ ). The PG-SGA score and biochemical values were not identified by the interaction between the groups at the time interval for measurement (Table 3).

Quality of Life: The overall quality of life $(\mathrm{F}=5.905$, $\mathrm{p}=0.707)$ score of functional area $(\mathrm{F}=0.613, \mathrm{p}=0.547)$ was not significantly correlated with the experimental group and the control group according to time interval for measurement(Table 3). 
Table 3. The effect of navigation program for gastric cancer patients with gastrectomy on distress, nutritional status, quality of life $(n=45)$

\begin{tabular}{|c|c|c|c|c|c|c|c|c|}
\hline \multirow{2}{*}{ Variables } & \multirow{2}{*}{ Group } & Preop. & $\begin{array}{c}\text { Postop. } \\
\text { 7-day }\end{array}$ & $\begin{array}{l}\text { Postop. } \\
\text { 1-month }\end{array}$ & $\begin{array}{l}\text { Postop. } \\
\text { 3-month }\end{array}$ & & \multirow{2}{*}{$\mathbf{F}$} & \multirow{2}{*}{$\mathbf{p}$} \\
\hline & & $\mathbf{M} \pm \mathbf{S D}$ & $\mathbf{M} \pm \mathbf{S D}$ & $\mathbf{M} \pm \mathbf{S D}$ & $\mathbf{M} \pm \mathbf{S D}$ & & & \\
\hline \multirow{2}{*}{ Distress } & Experimental & $3.70 \pm 1.14$ & $4.22 \pm 1.44$ & $4.70 \pm 0.82$ & $2.96 \pm 0.97$ & \multirow{2}{*}{$\begin{array}{c}\text { group } \\
\text { time } \\
\text { group*time }\end{array}$} & \multirow{2}{*}{$\begin{array}{c}3.351 \\
62.852 \\
5.298\end{array}$} & \multirow{2}{*}{$\begin{array}{c}0.74 \\
<0.001 \\
0.004\end{array}$} \\
\hline & Control & $4.00 \pm 1.41$ & $4.09 \pm 1.57$ & $5.59 \pm 0.95$ & $4.00 \pm 9.26$ & & & \\
\hline \multirow{2}{*}{ PG-SGA } & Experimental & $3.35 \pm 0.48$ & $4.96 \pm 1.02$ & $7.04 \pm 1.18$ & $4.35 \pm 1.22$ & \multirow{2}{*}{$\begin{array}{l}\text { group } \\
\text { time } \\
\text { group*time }\end{array}$} & \multirow{2}{*}{$\begin{array}{c}1.756 \\
244.877 \\
2.778\end{array}$} & \multirow{2}{*}{$\begin{array}{c}0.192 \\
<0.001 \\
0.053\end{array}$} \\
\hline & Control & $3.32 \pm 0.47$ & $5.05 \pm 1.21$ & $7.86 \pm 1.28$ & $4.95 \pm 1.64$ & & & \\
\hline \multirow{2}{*}{$\begin{array}{c}\text { Body weight } \\
\text { (kg) }\end{array}$} & Experimental & $66.84 \pm 11.19$ & & $64.23 \pm 11.02$ & $62.20 \pm 8.49$ & \multirow{2}{*}{$\begin{array}{l}\text { group } \\
\text { time } \\
\text { group*time }\end{array}$} & \multirow{2}{*}{$\begin{array}{c}4.461 \\
39.026 \\
4.390\end{array}$} & \multirow{2}{*}{$\begin{array}{c}0.041 \\
<0.001 \\
0.019\end{array}$} \\
\hline & Control & $62.44 \pm 9.03$ & & $57.35 \pm 7.05$ & $56.44 \pm 8.18$ & & & \\
\hline \multirow{2}{*}{$\begin{array}{l}\text { Hemoglobin } \\
(\mathrm{g} / \mathrm{dL})\end{array}$} & Experimental & $13.19 \pm 1.68$ & $11.63 \pm 1.17$ & $12.63 \pm 1.11$ & $12.64 \pm 1.34$ & \multirow{2}{*}{$\begin{array}{l}\text { group } \\
\text { time } \\
\text { group*time }\end{array}$} & \multirow{2}{*}{$\begin{array}{c}0.901 \\
38.218 \\
1.681\end{array}$} & \multirow{2}{*}{$\begin{array}{c}0.348 \\
<0.001 \\
0.186\end{array}$} \\
\hline & Control & $12.94 \pm 1.64$ & $10.84 \pm 1.43$ & $12.30 \pm 1.34$ & $12.67 \pm 1.35$ & & & \\
\hline \multirow{2}{*}{$\begin{array}{l}\text { Albumin } \\
(\mathrm{g} / \mathrm{dL})\end{array}$} & Experimental & $4.13 \pm 0.27$ & $3.36 \pm 0.29$ & $3.97 \pm 0.31$ & $4.11 \pm 0.25$ & \multirow{2}{*}{$\begin{array}{c}\text { group } \\
\text { time } \\
\text { group*time }\end{array}$} & \multirow{2}{*}{$\begin{array}{c}<0.001 \\
42.036 \\
1.406\end{array}$} & \multirow{2}{*}{$\begin{array}{c}0.997 \\
<0.001 \\
0.255\end{array}$} \\
\hline & Control & $4.22 \pm 0.36$ & $3.26 \pm 0.78$ & $3.89 \pm 0.47$ & $4.20 \pm 1.05$ & & & \\
\hline \multirow{2}{*}{$\begin{array}{l}\text { Protein } \\
(\mathrm{g} / \mathrm{dL})\end{array}$} & Experimental & $7.03 \pm 0.52$ & $6.12 \pm 0.59$ & $7.15 \pm 0.62$ & $7.04 \pm 0.50$ & \multirow{2}{*}{$\begin{array}{l}\text { group } \\
\text { time } \\
\text { group*time }\end{array}$} & \multirow{2}{*}{$\begin{array}{c}2.003 \\
64.961 \\
0.813\end{array}$} & \multirow{2}{*}{$\begin{array}{c}0.164 \\
<0.001 \\
0.494\end{array}$} \\
\hline & Control & $6.94 \pm 0.33$ & $5.84 \pm 0.66$ & $6.94 \pm 0.47$ & $6.88 \pm 0.48$ & & & \\
\hline \multirow{2}{*}{$\begin{array}{l}\text { Global health } \\
\text { status/QoL }\end{array}$} & Experimental & $62.68 \pm 6.08$ & & $55.40 \pm 6.01$ & $52.17 \pm 9.13$ & \multirow{2}{*}{$\begin{array}{l}\text { group } \\
\text { time } \\
\text { group*time }\end{array}$} & \multirow{2}{*}{$\begin{array}{c}0.098 \\
43.258 \\
5.905\end{array}$} & \multirow{2}{*}{$\begin{array}{c}0.490 \\
<0.001 \\
0.707\end{array}$} \\
\hline & Control & $62.12 \pm 6.15$ & & $55.12 \pm 6.15$ & $49.62 \pm 9.78$ & & & \\
\hline
\end{tabular}




\section{Satisfaction of Medical Services}

There was no difference in the medical service satisfaction for doctors between groups $(Z=-1.064, p=0.293)$, while there was a significant difference in the satisfaction of medical service for nurses between groups $(Z=-2.932$, $\mathrm{p}=0.003)$.Satisfaction in service area showed statistically significant difference $(Z=-2.651, p=0.007)$, and there was also significant difference in overall satisfaction with hospital between the experimental group and the control $\operatorname{group}(Z=-1.775, p=0.043)$ (Table 4).

Table 4. The effect of navigation program for gastric cancer patients with gastrectomy on satisfaction of medical service $(n=45)$

\begin{tabular}{|c|c|c|c|c|}
\hline \multirow[t]{2}{*}{ Variables } & $\begin{array}{l}\text { Experimental } \\
\quad(n=23)\end{array}$ & $\begin{array}{c}\text { Control } \\
(n=22)\end{array}$ & \multirow[t]{2}{*}{$\mathbf{Z}$} & \multirow{2}{*}{$p$} \\
\hline & $\mathbf{M} \pm \mathbf{S D}$ & $\mathbf{M} \pm \mathbf{S D}$ & & \\
\hline Doctors & $71.05 \pm 3.51$ & $70.21 \pm 3.54$ & -1.064 & 0.293 \\
\hline Interpersonal skills & $78.76 \pm 4.77$ & $79.39 \pm 4.58$ & -0.475 & 0.736 \\
\hline Technical skill & $73.26 \pm 8.96$ & $71.13 \pm 10.38$ & -0.864 & 0.395 \\
\hline Information provisions & $70.00 \pm 8.90$ & $70.360 \pm 8.51$ & -0.073 & 0.955 \\
\hline Availability & $61.84 \pm 6.08$ & $60.34 \pm 8.56$ & -0.481 & 0.620 \\
\hline Nurses & $84.34 \pm 6.05$ & $78.86 \pm 5.04$ & -2.932 & 0.003 \\
\hline Interpersonal skills & $85.94 \pm 11.32$ & $78.18 \pm 8.48$ & -2.462 & 0.013 \\
\hline Technical skill & $79.78 \pm 9.28$ & $79.46 \pm 9.01$ & -0.238 & 0.823 \\
\hline Information provisions & $90.57 \pm 10.86$ & $79.84 \pm 10.80$ & -3.227 & 0.001 \\
\hline Availability & $81.08 \pm 10.54$ & $77.95 \pm 8.22$ & -0.956 & 0.374 \\
\hline Service & $77.72 \pm 5.47$ & $72.90 \pm 4.97$ & -2.651 & 0.007 \\
\hline Other personnel & $83.40 \pm 9.96$ & $80.98 \pm 7.87$ & -1.075 & 0.283 \\
\hline Waiting time & $75.76 \pm 14.01$ & $70.00 \pm 12.19$ & -1.322 & 0.196 \\
\hline Access & $74.34 \pm 13.90$ & $67.72 \pm 11.97$ & -1.671 & 0.098 \\
\hline \multicolumn{5}{|l|}{ Other items } \\
\hline Exchange of information & $73.69 \pm 9.79$ & $70.00 \pm 10.91$ & -1.152 & 0.274 \\
\hline Comfort/cleanness & $71.08 \pm 5.21$ & $72.27 \pm 7.35$ & -0.630 & 0.608 \\
\hline General satisfaction & $86.30 \pm 12.17$ & $75.68 \pm 18.79$ & -1.975 & 0.043 \\
\hline
\end{tabular}




\section{Discussion}

The navigation program for gastric cancer patients developed in this study was based on the theory of transition ${ }^{[27]}$. This study was conducted in two stages. First, methodological study to develop a navigation program for gastric cancer patients by literature review and focus interview. Second, a quasi-experimental study was conducted to verify the effects of the navigation program.As a result of study, the nurse-led navigation program for gastric cancer patients was effective at reducing distress, improving nutritional status, and increasing satisfaction with healthcare services.

The distress significantly decreasedto the experimental group than the control group.It was consistent with previous studies ${ }^{[3,34]}$. These results represented that the intervention of various information, telephone counseling and support in this navigation program helped to reduce patient's distress. The distress of cancer patients might have a negative effect on the systemic condition, pain, medical service costs, treatment effects, satisfaction with medical care, quality of life, and even survival rates associated with cancer treatment. The stress intervention strategy might be contributed to improving patient satisfaction.

The change of the subjects' weight among the nutritional status was found to have significant interactions between two groups according to the measurement time. Similarly, Jung \& Lee ${ }^{[35]}$ 's study reported thatexperimental group who received nutritional education reported a lower weight loss than the control group. The experimental group gained confidence in food choice andshowedsignificant difference in weight loss with the increase in intake. Weight loss is the most commonly recognized indicator of malnutrition, especially weight loss after gastrectomy ${ }^{[36]}$. Thegastrectomy patients have various gastrointestinal symptoms. These symptoms eventually lead to weight $\operatorname{loss}^{[37]}$.In addition, the weight of the subjects gradually decreased in experimental group until 3 months after surgery. Itrepresented the continuous nutrition management needs after discharge. The results ofprevious study supported that intensive nutrition supply would be needed within 3 months after surgery ${ }^{[38]}$. Considering this result, the postoperative changes in gastric cancer can be predicted and explained to patients. Clinicians should provide care more effectivelytoward coping with malnutrition.

Although the PG-SGA score, biochemical tests i.e., serum hemoglobin, albumin, and protein levels were recovered by the time of measurement, however, these were not statistically significant. This was consistent with the previous gastric cancer studies ${ }^{[39]}$. Considering that the weight was continuously decreased for 3 months after surgery, it is necessary to avoid serious weight loss immediately after surgery. In addition, gastric cancer patients should take enough calorie intake to maintain the nutritional status. In future studies, it is necessary to understand the degree of postoperative eating habits and intake.

There were no significant differences inquality of life between two groups which is similar to previous navigation program for first diagnose with cancer ${ }^{[18,22]}$. However, other nurse-led navigation program showed positive effect to quality of life ${ }^{[40]}$. The gastric cancer quality of life had the lowest within 3 months after surgery, and they recovered continuously within 1 year after surgery ${ }^{[6,36,41]}$. The gastric cancer navigation program performed last intervention at 3 months after operation therefore, there should be caution in interpreting this study results. Future studies are needed to provide sufficient evidence to examine the impact of quality of life in long-term period including appropriate nursing care.

The result of verifying the effect of the navigation program on the satisfaction of medical services, the experimental group showed a significant difference for nurses. The interpersonal skills and information provision of subdomain of medical service for nurses weresignificant. This navigation program was designed for nurse-led intervention. The advanced nurses for gastric cancer provided the individual education, interest and support to patients. It might be the affirmative effect to increase the satisfaction level. This resultwas consistent with many navigation programsin enhancing the satisfaction of cancer patients ${ }^{[20,31,38,42]}$.

\section{Limitation}

The effect of navigation program was measuredafter 
3 months, when gastrointestinal symptoms of gastric cancer patients improved. The long-term effect of the quality of life changes after surgery was not verified. Therefore, it is necessary to conduct a follow-up study to measure the effect of the long-term period in order to evaluate the objective effect of the intervention program.

\section{Implications for Nursing}

Previous gastric cancer studies focused specific characteristics such as risk factor, cancer stage or setting i.e., community care ${ }^{[43,44]}$. Gastric cancer patients suffered diverse symptoms from diagnosis to discharge. This study focused on improving the outcome the patients by organizing individual nursing interventions systematically according to the step of each transition. This study tried to promote the attributes and conditions of the transition and to improve the result such as stress, nutrition status, quality of life and satisfaction through nursing care. The interventional framework of nursing treatment was Professional Navigation Framework by Fillion et $\mathrm{al}^{[28]}$, which allowed the elements of intervention to have theoretical basis. Through literature review and focus group interviews with patients and medical professionals, the program was induced to satisfy the needs of patients. A timely approach at each time of patient transition provided individual and ongoing integrated interventions to the clients.

\section{Conclusion}

Gastric cancer is the most common cancer in Korea.The improvement of cancer patients' survival rate led them to recognize a concept of chronic disease requiring long-term management. This study was to evaluate the effectiveness of navigation program for gastric cancer. The nurse-led navigation program for gastric cancer patients was positive effect to reduce the distress of the subjects, promoting the nutritional status, and enhance the satisfaction of medical services. This study contributed to gastric cancer patients' quality of life improvement. It is suggested to conduct long-term follow-up research to measure quality of life changes due to the navigation program. Furthermore, it is necessary to continuously pay attention to the quality of life of vulnerable population such as elderly gastric cancer patients.
Knowledge Translation

- This study focused on improving the outcome the patients by organizing individual nursing interventions systematically based on the theory of transition.

- The nurse-led navigation program for gastric cancer patients was effective at reducing distress, improving nutritional status, and increasing satisfaction with healthcare services.

- The nurse-led navigator program provided individual education, attention, and support to gastric cancer patients to increase satisfaction, which had a positive effect.

Source Funding: This work was supported by the National Research Foundation of Korea(NRF) grant funded by the Korea government(MSIT) (No 2019R1G1A1100444)

\section{Conflict of Interest : None}

Ethical Clearance: This research has ethical clearance from the Institutional Review Board of Konyang University Hospital(KYUH 2015-09-004-002)

\section{References}

1. National Cancer Center. Annual report of cancer statistics in Korea in 2014. Ministry of Health and Welfare. 2016.

2. Ferlay J, Colombet M, Soerjomataram I, Mathers C, Parkin DM, Piñeros M, et al. Estimating the global cancer incidence and mortality in 2018: GLOBOCAN sources and methods. International journal of cancer. 2019;144(8):1941-53.

3. Chaput G, Sussman J. Integrating primary care providers through the seasons of survivorship. Current Oncology. 2019;26(1):48-54.

4. Lagergren P, Schandl A, Aaronson NK, Adami H, de Lorenzo F, Denis L, et al. Cancer survivorship: an integral part of Europe's research agenda. Molecular oncology. 2019;13(3):624-35.

5. Horner K, Ludman EJ, Mccorkle R, Canfield E, Flaherty L, Min J, et al. An oncology nurse navigator program designed to eliminate gaps in 
early cancer care. Clin J Oncol Nurs. 2013;17(1).

6. Park Y, Yoon S, Kang S, Han S, Kang E. Nutritional status and dietary change after gastrectomy of gastric cancer patients. Korean Journal of Community Nutrition. 2012;17(1):101-8.

7. Davis-Evans C. Alleviating anxiety and preventing panic attacks in the surgical patient. AORN J. 2013;97(3):354-64.

8. National Comprehensive Cancer Network. Distress management. Clinical practice guidelines. Journal of the National Comprehensive Cancer Network: JNCCN. 2003;1(3):344-74.

9. Park IS, Kim EM, Oh PJ, Kim SJ, Kim HJ, Kim $\mathrm{BK}$, et al. Developing telephone guidelines for symptom management of cancer for outpatients with cancer after chemotherapy. Journal of Korean Clinical Nursing Research. 2012;18(2):317-28.

10. Choi JY, Kang HS. Effects of a Home-based Exercise Program for Patients with Stomach Cancer Receiving Oral Chemotherapy after Surgery. Journal of Korean Academy of Nursing. 2012;42(1).

11. Xie F, Wang Y, Peng L, Lin F, He Y, Jiang Z. Beneficial effect of educational and nutritional intervention on the nutritional status and compliance of gastric cancer patients undergoing chemotherapy: a randomized trial. Nutr Cancer. 2017;69(5):762-71.

12. Fowler T, Steakley C, Garcia AR, Kwok J, Bennett LM. Reducing disparities in the burden of cancer: the role of patient navigators. PLoS Med. 2006;3(7):e193.

13. Freeman H. Voices of a broken system. Real people, real voices.Bethesda: National Cancer Institute. 2001.

14. American College of Surgeons. Commission on Cancer. Cancer program standards 2012: Ensuring patient-centered care. American College of Surgeons; 2012.

15. Wells KJ, Battaglia TA, Dudley DJ, Garcia R, Greene A, Calhoun E, et al. Patient navigation: state of the art or is it science? Cancer. 2008;113(8):19992010 .

16. Chillakunnel Hussain Rawther S, Pai MS, Fernandes DJ, Mathew S, Binu VS, Chakrabarty J, et al. A
Randomized controlled trial to evaluate the impact of a Nurse Navigator Programme on outcomes of people with breast cancer: study protocol. J Adv Nurs. 2017;73(4):977-88.

17. Lagergren $\mathrm{P}$, Schandl A, Aaronson NK, Adami H, de Lorenzo F, Denis L, et al. Cancer survivorship: an integral part of Europe's research agenda. Molecular oncology. 2019;13(3):624-35.

18. Fiscella K, Whitley E, Hendren S, Raich $\mathrm{P}$, Humiston S, Winters $P$, et al. No title. Patient navigation for breast and colorectal cancer treatment: a randomized trial. 2012.

19. Hacking B, Wallace L, Scott S, Kosmala-Anderson J, Belkora J, McNeill A. Testing the feasibility, acceptability and effectiveness of a 'decision navigation'intervention for early stage prostate cancer patients in Scotland-a randomised controlled trial. Psychooncology. 2013;22(5):1017-24.

20. Park KA, Oh YJ, Kim KM, Eum SY, Cho $\mathrm{MH}$, Son $\mathrm{YH}$, et al. Navigation programs, are they helpful for perioperative care with thyroid cancer patients? European journal of cancer care. 2017;26(4):e12592.

21. Gilbert JE, Green E, Lankshear S, Hughes E, Burkoski V, Sawka C. Nurses as patient navigators in cancer diagnosis: review, consultation and model design. European journal of cancer care. 2011;20(2):228-36.

22. Mertz BG, Dunn-Henriksen AK, Kroman N, Johansen C, Andersen KG, Andersson M, et al. The effects of individually tailored nurse navigation for patients with newly diagnosed breast cancer: a randomized pilot study. Acta Oncol. 2017;56(12):1682-9.

23. Ramirez AG, Choi BY, Munoz E, Perez A, Gallion KJ, Moreno PI, et al. Assessing the effect of patient navigator assistance for psychosocial support services on health-related quality of life in a randomized clinical trial in Latino breast, prostate, and colorectal cancer survivors. Cancer. 2020;126(5):1112-23.

24. Horner K, Ludman EJ, Mccorkle R, Canfield E, Flaherty L, Min J, et al. An oncology nurse navigator program designed to eliminate gaps in early cancer care. Clin J Oncol Nurs. 2013;17(1). 
25. Lee KE, Son YG, Ryu SW. Validation of geriatric nutritional risk index and percent weight loss as a predictor of post-operative complications after gastrectomy in elderly patients. Journal of Clinical Nutrition. 2014;6(1):30-6.

26. Hong YS, Park JY, Kim SH, Kim SA, Kim YH. Effects of a navigation program for patients with newly diagnosed gastric cancer: A randomized controlled trial. Asian Oncology Nursing. 2016;16(3):132-8.

27. Meleis AI, Sawyer LM, Im E, Messias DKH, Schumacher K. Experiencing transitions: an emerging middle-range theory. Advances in nursing science. 2000;23(1):12-28.

28. Fillion L, Cook S, Veillette A, Aubin M, De Serres $\mathrm{M}$, Rainville $\mathrm{F}$, et al. Professional navigation framework: elaboration and validation in a Canadian context. Oncology nursing forum; ; 2012.

29. Kim JH, Kang JI, Kim T, Kim H, Kim TS, Kim HK. Development of recommendations for distress management toward improvement of quality of life in cancer patients. Seoul: Ministry of Health \& Welfare. 2009.

30. Ottery FD. Definition of standardized nutritional assessment and interventional pathways in oncology. Nutrition. 1996;12(1):S15-9.

31. Vickery CW, Blazeby JM, Conroy T, Arraras J, Sezer O, Koller M, et al. Development of an EORTC disease-specific quality of life module for use in patients with gastric cancer. Eur J Cancer. 2001;37(8):966-71.

32. Blazeby J, Cull A, Groenvold M, Bottomley A. Guidelines for developing quality of life questionnaires. Brussels: EOETC Publications. 2001.

33. Ferrante JM, Chen P, Kim S. The effect of patient navigation on time to diagnosis, anxiety, and satisfaction in urban minority women with abnormal mammograms: a randomized controlled trial. Journal of Urban Health. 2008;85(1):114-24.

34. Swanson J, Koch L. The role of the oncology nurse navigator in distress management of adult inpatients with cancer: a retrospective study. Oncology Nursing Forum; ; 2010.
35. Jung Y, Lee J. Effect of Nutrition Education on the Eating Habits and Quality of Life of Gastric Cancer Outpatients Undergoing Gastrectomy. Korean Journal of Community Nutrition. 2018;23(2):16273.

36. Kim JH, Choi JY. Postoperative changes in body weight, anxiety, depression, and quality of life after radical gastrectomy among patients with gastric cancer. Asian Oncology Nursing. 2014;14(3):13945.

37. Kim B, Choi JY. Factors associated with early nutritional status after radical gastrectomy in patients with gastric cancer. Asian Oncology Nursing. 2015;15(4):219-27.

38. Hyun SJ. Pre- and Post-Operative Health Status and Quality of Life Among Elderly Patients with Gastric Cancer [dissertation]. Daegu: Keimyung university

39. Oh C, Kim D, Oh S, Choi M, Noh J, Sohn T, et al. Changes of the preoperative and postoperative nutritional statuses in patients with gastric cancer and assessment of the nutritional factors that are correlated with short-term postoperative complications. Journal of Gastric Cancer. 2010;10(1):5-12.

40. Lee T, Ko I, Lee I, Kim E, Shin M, Roh S, et al. Effects of nurse navigators on health outcomes of cancer patients. Cancer Nurs. 2011;34(5):376-84.

41. Kong $\mathrm{H}, \mathrm{Kwon} \mathrm{OK}, \mathrm{Yu} \mathrm{W}$. Changes of quality of life after gastric cancer surgery. Journal of gastric cancer. 2012;12(3):194.

42. Wells KJ, Winters PC, Jean-Pierre P, WarrenMears V, Post D, Van Duyn, Mary Ann S, et al. Effect of patient navigation on satisfaction with cancer-related care. Supportive Care in Cancer. 2016;24(4):1729-53.

43. Bilgin S, Gozum S. Effect of nursing care given at home on the quality of life of patients with stomach cancer and their family caregivers' nursing care. European journal of cancer care. 2018;27(2):e12567.

44. Sun Y, Li M. Genetic polymorphism of miR-146a is associated with gastric cancer risk: a meta-analysis. European journal of cancer care. 2017;26(2):e12355. 